ORIGINAL ARTICLE

\title{
Household gas cooking: a risk factor for respiratory illnesses in preschool children
}

\author{
T W Wong, T S Yu, H J Liv, A H S Wong
}

Arch Dis Child 2004;89:631-636. doi: 10.1136/adc.2003.030601

See end of article for authors' affiliations

.....................

Correspondence to: Prof. T W Wong, Department of Community and Family Medicine, The Chinese University of Hong Kong, 4/F, School of Public Health, Prince of Wales Hospital, Shatin, NT, Hong Kong; twwong@cuhk.edu.hk

Accepted 26 September 2003

\begin{abstract}
Aims: To explore the association of household gas cooking and respiratory illnesses in preschool children and their relation to outdoor air pollution.

Methods: Cross-sectional study among households that used gas stoves for cooking in two housing estates with contrasting air qualities in Hong Kong. A structured questionnaire was administered to parents of 426 children aged $0-6$ years on their exposure to gas cooking and passive smoking, and the prevalence of respiratory illnesses.

Results: A total of 111 children (26.1\%) were reported to have one or more respiratory illnesses (allergic rhinitis, asthma, bronchitis, sinusitis, and pneumonia). Of these, 21 (18.9\%), 41 (36.9\%), and 49 (44.1\%) children were from households that cooked once, twice, and three times a day with gas. Hierarchical logistic regression models adjusting for socioeconomic, demographic, and indoor risk factors including passive smoking showed that household gas cooking was positively associated with respiratory illnesses. There was a dose-response relation between the frequency of gas cooking and the prevalence of respiratory illnesses in the estate with lower outdoor air pollution $(O R=6.1$ and 3.2 respectively, for cooking three and two meals a day, compared to one meal a day). This relation was not observed in the more polluted estate. The association between the presence of a cigarette smoker in the household and the prevalence of respiratory illnesses was not significant.

Conclusions: As gas cooking is common in urban households, the findings could have important public health implications.
\end{abstract}

I an urban community, the outdoor environment is widely contaminated by complex mixtures of gaseous and particulate air pollutants that are produced by combustion or industrial discharges. The indoor environment, besides being affected by air pollutants in the outdoor environment, also contains various chemicals released from human activities, furniture, and building materials. Because people spend more time indoors than outdoors, research interests have been focused on the potential hazards of indoor air pollution on respiratory health. Domestic combustion of fossil fuels, in particular, the use of gas appliances in a poorly ventilated kitchen, produces high indoor concentrations of particulates, nitrogen dioxide, and nitric oxide. ${ }^{1}$ However, the extent to which cooking with gas is hazardous to human health still remains unclear, largely because of the difficulties in measuring individual exposures and the inconsistent epidemiological findings.

Evidence for an association between domestic gas cooking and heating, and respiratory illnesses is not consistent..$^{2-4}$ Environmental tobacco smoke and outdoor air pollution are competing risk factors that affect respiratory health. These two factors may influence the association between household gas cooking and respiratory health. Most studies exploring this association were conducted in primary school children or adults. $^{25-7}$ Both groups are susceptible to outdoor air pollution. Even if personal monitoring is used to assess exposure, it is often difficult to attribute the health outcome separately to indoor or outdoor air pollutants. The study of preschool children who spend most of their time indoors and are therefore less exposed to outdoor air pollutants, provides a good opportunity to identify the possible impact of household gas cooking on their respiratory health.

Hong Kong has a total area of $1100 \mathrm{~km}^{2}$ and a population of 6.8 million. Most residents live in multi-storeyed apartment buildings. Piped "town gas" (consisting mainly of methane and hydrogen derived from naphtha) and bottled liquid petroleum gas (mainly butane) are the most common fuels used for household cooking. The climate is sub-tropical, with hot humid summers and cool dry winters. Domestic heating is normally not required, except in the colder days of winter. Electric heaters (but not gas) are used for this purpose. To explore the association between household gas cooking and respiratory illnesses in preschool children and their relations to outdoor air pollution, we conducted a study on preschool children in two residential estates with contrasting levels of outdoor air pollution. We tested the hypothesis that frequent gas cooking was associated with a higher risk of respiratory illnesses among preschool children in these households, and that the level of outdoor air pollution may affect this relation.

\section{METHODS}

\section{Study sites and subjects}

Two private residential estates (estates A and B) in Hong Kong were selected as study sites. Estate A was located at a town centre adjacent to an industrial area, a main road, and a municipal incinerator. Estate B was situated along the seashore off the main road, and was much further away from similar industrial areas and other sources of pollution (fig 1). The mean annual concentrations of several major air pollutants $\left(\mathrm{PM}_{10}, \mathrm{SO}_{2}, \mathrm{NO}_{2}, \mathrm{NO}\right)$ in the air quality monitoring station closest to estate B were about 30\% lower than that adjacent to estate A (table 1). We considered estate A to be a high air pollution area, and estate $\mathrm{B}$ as a low air pollution area. Both estates consisted of several similar buildings, each made up of multi-storeyed apartments. Residents of both estates were typically middle-class families. One building was randomly selected from each estate and all households in the selected block were included in the survey. The buildings in the two estates were similar in their design layout. The area 


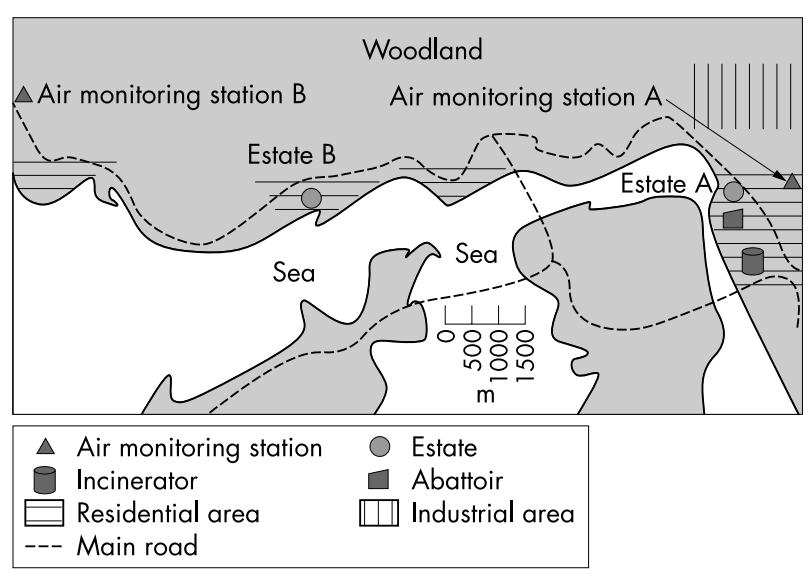

Figure 1 Location of the two estates and air monitoring stations.

of each apartment ranged from 50 to $70 \mathrm{~m}^{2}$, where three to five family members lived. In both estates, all households used piped gas for cooking. Parents of preschool children aged 6 or less, who had lived in the estates for at least one year, were recruited in the study.

\section{Study design}

A cross-sectional study was conducted among residents in the two estates over a 10 week period (mid April to early July 1994). A structured questionnaire was used in a face-to-face interview of the children's parents at their residence. Information on children's exposures to sources of indoor air pollutants (passive smoking and gas cooking), their point prevalence of respiratory illnesses (that is, current illnesses at the time of the interview), and the sociodemographic characteristics of the households were obtained. Respiratory illnesses included allergic rhinitis, bronchitis, bronchial asthma, and pneumonia. To minimise potential misclassification of these illnesses in the interpretation of these diseases, only doctor confirmed respiratory illnesses were recorded. The frequency of household gas cooking was defined as the number of meals cooked per day at home in the past month. Children's exposure to passive smoking was defined as the presence of one or more household members who were regular smokers up to the month before the interview. Information on other possible indoor pollutantsburning joss sticks (incense) and mosquito coils, and keeping furry stuffed soft toys and pets at home-and other potential confounders (whether residents usually kept their windows open, and their subjective assessment of the indoor air quality in their homes) were also obtained. This study was approved by the Ethical Committee of The Chinese University of Hong Kong.

\section{Statistical analysis}

All data were entered into a computerised database. Bivariate analysis and multivariate logistic regression analysis were performed to estimate crude odds ratios (OR), adjusted odds

Table 1 Annual mean concentrations of air pollutants $\left(\mu \mathrm{g} / \mathrm{m}^{3}\right)$

\begin{tabular}{lll}
\hline Air pollutant & Estate $\mathbf{A}$ & Estate B \\
\hline $\mathrm{SO}_{2}$ & 30 & 23 \\
$\mathrm{NO}_{2}$ & 59 & 45 \\
$\mathrm{PO}_{10}$ & 60 & 24 \\
& 62 & 41 \\
\hline
\end{tabular}

ratios, and their $95 \%$ confidence intervals (95\% CI) with SAS software (version 8.01; SAS Institute, Cary, NC). To assess the effect of household gas cooking on the risk of respiratory illnesses, four hierarchical models were built with various combinations of covariates. Model 1 only included two exposure variables (gas cooking frequency and passive smoking). In model 2, sociodemographic variables (gender, age, and parents' occupation) were added. In model 3, we adjusted for other possible indoor sources of pollution (incense burning, the use of extraction fans or hoods in the kitchen, keeping pets and soft toys), whether windows were usually kept open, and the outdoor environment (which estate they lived in) to estimate the adjusted ORs. In model 4 , apart from all the variables in model 3, we added the respondents' subjective self-satisfaction with their indoor air quality to adjust for the potential recall bias in reporting their children's illnesses. We also performed multiple regression analyses stratified by estate in order to assess whether the relation between gas cooking and the risk of respiratory illnesses would be different in children living in estates with different levels of outdoor air pollutants. The analyses were limited to 426 children for whom complete information was available on respiratory illnesses; 14 children (3.3\%) were excluded for this reason. We also performed similar analyses with allergic rhinitis (the predominant illness reported among the children) as the dependent variable.

\section{RESULTS}

Description of subjects, prevalence of risk factors, and respiratory illnesses

There were 616 households in the two estates: 225 (36.5\%) households from estate A and 391 (63.5\%) from estate B. All were invited to participate. A total of 520 households (response rate $85.3 \%$ ) responded: 199 households in estate A (response rate $88.6 \%$ ), and 321 households in estate B (response rate $82.1 \%$ ). Of these, 359 households (134 in estate A and 225 in Estate B) had preschool children aged 6 and below. Parents of 426 preschool children from these households were interviewed; 154 (36.2\%) children came from estate A and 272 (63.8\%) from estate B. On average, there were 1.1 children per household in estate A and 1.2 children per household in estate B; $74.9 \%$ of households had only one child, $23.8 \%$ had two, and $1.3 \%$ had three. Table 2 presents their demographic characteristics, the frequency of gas cooking, exposure to passive smoking, and other sources of indoor air pollution. Apart from gender, the distributions of these variables were broadly similar between the children from the two estates. Among all subjects, 95 (22.3\%) children were from households with a frequency of gas cooking of one meal per day, 185 (43.4\%) with two meals per day, and 146 $(34.3 \%)$ with three meals per day. Ninety two $(21.6 \%)$ children were exposed to passive smoking. Gas was the only fuel used for cooking in all the households surveyed.

A total of 111 children (26.1\%) reportedly had one or more doctor confirmed respiratory illnesses at the time of the interview (point prevalence). Among those children with respiratory illnesses, $99(89.2 \%)$ reported having allergic rhinitis, 10 (9\%) bronchitis, eight (7.2\%) asthma, four (3.6\%) sinusitis, and two (1.8\%) pneumonia. ${ }^{*}$

Relation between risk factors and respiratory illnesses In the bivariate analysis, the odds of respiratory illnesses were associated with being male, an older age, parents' dissatisfaction with the indoor air quality, and residing in estate A. Interestingly, the prevalence of respiratory illnesses among children in estate A was almost three times that in estate B (table 3). Hierarchical logistic regression analyses

*Data referred to in this paragraph are not shown in the tables. 
Table 2 Sociodemographic characteristics of subjects in two estates

\begin{tabular}{|c|c|c|c|c|c|c|}
\hline & \multicolumn{2}{|c|}{ Estate $\mathbf{A}$} & \multicolumn{2}{|c|}{ Estate B } & \multirow[b]{2}{*}{ Total $^{*}$} & \multirow[b]{2}{*}{ p value } \\
\hline & No. & $\%$ & No. & $\%$ & & \\
\hline Gender & & & & & & 0.04 \\
\hline Female & 63 & 42.9 & 144 & 53.5 & 207 & \\
\hline Male & 84 & 57.1 & 125 & 46.5 & 209 & \\
\hline Subtotal & 147 & & 269 & & 416 & \\
\hline Age (years) & & & & & & 0.63 \\
\hline $0-1$ & 27 & 17.5 & 61 & 22.4 & 88 & \\
\hline $2-3$ & 53 & 34.4 & 106 & 39.0 & 159.0 & \\
\hline $4-6$ & 74 & 48.1 & 105 & 38.6 & 179 & \\
\hline Subtotal & 154 & & 272 & & 426 & \\
\hline Parents' job & & & & & & 0.92 \\
\hline White collar & 71 & 46.1 & 124 & 45.6 & 195 & \\
\hline Blue collar & 83 & 53.9 & 148 & 54.4 & 231 & \\
\hline Subtotal & 154 & & 272 & & 426 & \\
\hline Household gas cooking frequency & & & & & & 0.94 \\
\hline $1 \mathrm{meal} /$ day & 35 & 22.7 & 60 & 22.1 & 95 & \\
\hline 2 meals $/$ day & 65 & 42.2 & 120 & 44.1 & 185 & \\
\hline 3 meals $/$ day & 54 & 35.1 & 92 & 33.8 & 146 & \\
\hline Subtotal & 154 & & 272 & & 426 & \\
\hline Exposure to passive smoking & & & & & & 0.80 \\
\hline Yes & 32 & 21.1 & 60 & 22.1 & 92 & \\
\hline No & 120 & 78.9 & 211 & 77.9 & 331 & \\
\hline Subtotal & 152 & & 271 & & 423 & \\
\hline Respiratory disease & & & & & & $<0.001$ \\
\hline Yes & 68 & 45.3 & 43 & 16.4 & 111 & \\
\hline No & 82 & 54.7 & 219 & 83.6 & 301 & \\
\hline Subtotal & 150 & & 262 & & 412 & \\
\hline
\end{tabular}

Table 3 Factors associated with having a respiratory illness

\begin{tabular}{|c|c|c|c|c|c|c|c|c|}
\hline & \multicolumn{4}{|c|}{ Estate A } & \multicolumn{4}{|c|}{ Estate B } \\
\hline & \multicolumn{4}{|c|}{ Having illness } & \multicolumn{4}{|c|}{ Having illness } \\
\hline & $n$ & $\%^{*}$ & OR & $95 \% \mathrm{Cl}$ & $n$ & $\%^{*}$ & OR & $95 \% \mathrm{Cl}$ \\
\hline \multicolumn{9}{|l|}{ Gender } \\
\hline Female & 25 & 35.7 & 1 & & 22 & 15.0 & 1 & \\
\hline Male & 43 & 51.2 & 1.89 & 0.99 to 3.61 & 21 & 16.8 & 1.15 & 0.60 to 2.20 \\
\hline \multicolumn{9}{|l|}{ Age (years) } \\
\hline $0-1$ & 7 & 25.9 & 1 & & 7 & 11.5 & 1 & \\
\hline $2-3$ & 23 & 43.4 & 2.19 & 0.79 to 6.06 & 15 & 14.2 & 1.27 & 0.49 to 3.32 \\
\hline $4-6$ & 38 & 51.4 & 3.02 & 1.14 to 7.99 & 21.0 & 20.0 & 1.93 & 0.77 to 4.85 \\
\hline \multicolumn{9}{|l|}{ Parents' job } \\
\hline Non-white collar & 34 & 40.9 & 1 & & 29 & 19.6 & 1 & \\
\hline White collar & 34 & 47.9 & 1.32 & 0.70 to 2.51 & 14 & 11.3 & 0.52 & 0.26 to 1.04 \\
\hline \multicolumn{9}{|c|}{ Household gas cooking frequency } \\
\hline 1 meal $/$ day & 16 & 45.7 & 1 & & 5 & 8.3 & 1 & \\
\hline 2 meals/day & 24 & 36.9 & 0.70 & 0.30 to 1.60 & 17 & 14.2 & 1.82 & 0.64 to 5.19 \\
\hline 3 meals/day & 28 & 51.6 & 1.27 & 0.55 to 3.00 & 21 & 22.8 & 3.25 & 1.15 to 9.18 \\
\hline \multicolumn{9}{|c|}{ Exposure to passive smoking } \\
\hline No & 53 & 43.4 & 1 & & 33 & 15.6 & 1 & \\
\hline Yes & 15 & 46.9 & 1.14 & 0.53 to 2.51 & 10 & 16.7 & 1.08 & 0.50 to 2.35 \\
\hline \multicolumn{9}{|c|}{ Extraction fan/hood in kitchen } \\
\hline No & 4 & 80.0 & 1 & 1 & 1 & 16.7 & 1 & \\
\hline Yes & 64 & 42.9 & 0.19 & 0.02 to 1.72 & 42 & 15.8 & 0.93 & 0.11 to 8.23 \\
\hline \multicolumn{9}{|l|}{ Usually open window } \\
\hline No & 12 & 40 & 1 & & 7 & 11.9 & 1 & \\
\hline Yes & 56 & 45.2 & 1.51 & 0.64 to 3.59 & 36 & 16.9 & 1.23 & 0.55 to 2.78 \\
\hline \multicolumn{9}{|l|}{ Burn joss sticks } \\
\hline No & 45 & 42.9 & 1 & & 29 & 14.2 & 1 & \\
\hline Yes & 23 & 46.9 & 1.18 & 0.60 to 2.33 & 14 & 20.6 & 1.56 & 0.77 to 3.17 \\
\hline \multicolumn{9}{|c|}{ Stuffed soft toys at home } \\
\hline No & 32 & 45.1 & 1 & & 24 & 17.5 & 1 & \\
\hline Yes & 36 & 43.4 & 0.93 & 0.49 to 1.77 & 19 & 14.1 & 0.77 & 0.40 to 1.49 \\
\hline \multicolumn{9}{|l|}{ Pets at home } \\
\hline No & 65 & 43.3 & 1 & & 38 & 14.9 & 1 & \\
\hline Yes & 3 & 75.0 & 3.92 & 0.40 to 38.4 & 5 & 27.8 & 2.19 & 0.74 to 6.49 \\
\hline \multicolumn{9}{|c|}{ Self-satisfied with indoor air quality } \\
\hline Yes & 36 & 41.9 & 1 & & 16 & 8.6 & 1 & \\
\hline No & 32 & 47.1 & 1.23 & 0.65 to 2.34 & 27 & 31.8 & 4.98 & 2.50 to 9.88 \\
\hline
\end{tabular}


showed that the odds of household gas cooking were positively and monotonically associated with respiratory illnesses after controlling for the other covariates (table 4). For example, in model 4, controlling for all covariates, children in households in which three or more meals per day were cooked were 2.6 times more likely to have a respiratory illness at the time of interview compared to children in households where only one meal per day was cooked. Reference groups in this model were: the absence of risk factors (passive smoking, extraction fan or hood, burning joss sticks, keeping stuffed toys and pets), windows usually kept closed, female gender, age group $0-1$ years, a non-white collar job of the parent, estate B, and being satisfied with the indoor air quality.

Table 5 shows the adjusted ORs and the 95\% confidence intervals of the frequencies of household gas cooking for respiratory illnesses stratified by estate. The two models were adjusted for all the other variables listed in model 4 (as shown in table 4). In the model for estate B, the estate with a lower concentration of outdoor air pollutants, exposure to household gas cooking was a risk factor for respiratory illnesses. A monotonic, dose-response relation with the frequency of gas cooking was observed, with the OR increasing from 3.2 (at cooking two meals a day) to 6.1 (at cooking three meals a day), and the latter reaching statistical significance. By contrast, no significant association between gas cooking and respiratory illnesses was observed in the model for the more polluted estate A, although the OR was above unity (at 1.7) for children exposed to cooking three meals a day. When we separately analysed the association between gas cooking and allergic rhinitis in the models described above, the results were similar to those for all respiratory illnesses.

\section{DISCUSSION}

We found a significant, dose-response association between household gas cooking and the prevalence of respiratory illnesses in preschool children in a residential estate with low outdoor air pollution, after controlling for potential confounding factors. Our study provides additional evidence that household gas cooking increases the risk of respiratory illnesses among preschool children.

Most previous studies addressing the relation between household gas cooking and respiratory illnesses were based on a dichotomous variable of the exposure, that is, gas stove users and non-users. ${ }^{39}$ In this study, we studied the frequency of gas cooking and evaluated the dose-response relation between the frequency of gas cooking and the prevalence of respiratory illnesses among preschool children. The lack of a clear association reported in some studies may be partly due to a crude estimate of exposure. Different cooking methods might also have explained the discrepancies in the study results. In contrast to the cooking habits in other countries, stir frying with a strong flame, which generates large amounts of cooking oil fumes, ${ }^{1}$ is a favourite Chinese cooking style.

Our subjects were preschool children who spent most of their time in the home environment and who were more susceptible to respiratory illnesses than older children. This

\begin{tabular}{|c|c|c|c|c|c|c|c|c|}
\hline & \multicolumn{2}{|c|}{ Model 1} & \multicolumn{2}{|c|}{ Model 2} & \multicolumn{2}{|c|}{ Model 3} & \multicolumn{2}{|c|}{ Model 4} \\
\hline & OR & $95 \% \mathrm{Cl}$ & OR & $95 \% \mathrm{Cl}$ & OR & $95 \% \mathrm{Cl}$ & OR & $95 \% \mathrm{Cl}$ \\
\hline \multicolumn{9}{|c|}{ Household gas cooking frequency } \\
\hline $1 \mathrm{meal} / \mathrm{day}$ & 1 & & 1 & & 1 & & 1 & \\
\hline 2 meals/day & 0.99 & 0.54 to 1.79 & 0.98 & 0.53 to 1.83 & 1.07 & 0.54 to 2.10 & 1.28 & 0.64 to 2.59 \\
\hline 3 meals/day & 1.68 & 0.92 to 3.05 & 1.87 & 1.00 to 3.47 & 2.19 & 1.09 to 4.39 & 2.64 & 1.28 to 5.43 \\
\hline \multicolumn{9}{|c|}{ Exposure to passive smoking } \\
\hline No & 1 & & 1 & & 1 & & 1 & \\
\hline Yes & 1.09 & 0.65 to 1.85 & 0.99 & 0.57 to 1.71 & 0.95 & 0.52 to 1.72 & 0.92 & 0.50 to 1.67 \\
\hline \multicolumn{9}{|l|}{ Gender } \\
\hline Female & & & 1 & & 1 & & 1 & \\
\hline Male & & & 1.66 & 1.05 to 2.62 & 1.50 & 0.92 to 2.46 & 1.67 & 1.00 to 2.77 \\
\hline \multicolumn{9}{|l|}{ Age (years) } \\
\hline $0-1$ & & & 1 & & 1 & & 1 & \\
\hline $2-3$ & & & 1.66 & 0.83 to 3.33 & 1.55 & 0.75 to 3.23 & 1.67 & 0.79 to 3.52 \\
\hline $4-6$ & & & 2.37 & 1.22 to 4.63 & 1.94 & 0.96 to 3.92 & 2.03 & 0.99 to 4.17 \\
\hline \multicolumn{9}{|l|}{ Parents' job } \\
\hline Non-white collar & & & 1 & & 1 & & 1 & \\
\hline White collar & & & 0.86 & 0.54 to 1.38 & 0.91 & 0.55 to 1.51 & 1.00 & 0.60 to 1.68 \\
\hline \multicolumn{9}{|c|}{ Extraction fan/hood in kitchen } \\
\hline No & & & & & 1 & & 1 & \\
\hline Yes & & & & & 0.36 & 0.09 to 1.48 & 0.27 & 0.06 to 1.19 \\
\hline \multicolumn{9}{|c|}{ Usually open window } \\
\hline No & & & & & 1 & & 1 & \\
\hline Yes & & & & & 1.16 & 0.63 to 2.15 & 1.26 & 0.67 to 2.35 \\
\hline \multicolumn{9}{|l|}{ Burn joss sticks } \\
\hline No & & & & & 1 & & 1 & \\
\hline Yes & & & & & 1.43 & 0.83 to 2.44 & 1.35 & 0.77 to 2.35 \\
\hline \multicolumn{9}{|c|}{ Stuffed soft toys at home } \\
\hline No & & & & & 1 & & 1 & \\
\hline Yes & & & & & 0.88 & 0.54 to 1.44 & 0.82 & 0.50 to 1.37 \\
\hline \multicolumn{9}{|l|}{ Pets at home } \\
\hline No & & & & & 1 & & 1 & \\
\hline Yes & & & & & 1.66 & 0.57 to 4.81 & 1.76 & 0.61 to 5.13 \\
\hline \multicolumn{9}{|l|}{ Estate } \\
\hline B & & & & & 1 & & 1 & \\
\hline A & & & & & 4.49 & 2.74 to 7.34 & 4.09 & 2.47 to 6.77 \\
\hline \multicolumn{9}{|c|}{ Self-satisfied with indoor air quality } \\
\hline Yes & & & & & & & 1 & \\
\hline No & & & & & & & 2.95 & 1.76 to 4.96 \\
\hline
\end{tabular}




\begin{tabular}{|c|c|c|c|c|}
\hline & \multicolumn{2}{|c|}{ Estate $\mathbf{A}$} & \multicolumn{2}{|c|}{ Estate B } \\
\hline & OR & $95 \% \mathrm{Cl}$ & OR & $95 \% \mathrm{Cl}$ \\
\hline \multicolumn{5}{|c|}{ Household gas cooking frequency } \\
\hline 1 meal/day & 1 & & 1 & \\
\hline 2 meals/day & 0.78 & $0.31-1.98$ & 3.19 & $0.92-11.04$ \\
\hline $3 \mathrm{meals} /$ day & 1.72 & $0.64-4.60$ & 6.12 & $1.73-21.59$ \\
\hline \multicolumn{5}{|c|}{ Exposure to passive smoking } \\
\hline No & 1 & & 1 & \\
\hline Yes & 1.11 & $0.46-2.68$ & 0.81 & $0.33-1.97$ \\
\hline
\end{tabular}

*Adjusted for gender, age, parents' job, extraction fan/hood in kitchen, burning joss-sticks, stuffed soft toys, pets at home, opening windows, and self-satisfaction with indoor air quality.

reduces potential confounding effects due to exposures to other environments such as the school.

In areas with high ambient concentrations of $\mathrm{NO}_{2}$, children might be exposed to higher $\mathrm{NO}_{2}$ levels originating from outdoor sources by diffusion, even in the absence of gas cooking. ${ }^{10}$ By contrast, gas cooking may be an important source of $\mathrm{NO}_{2}$ in homes with low outdoor levels. The contribution of gas cooking to the total $\mathrm{NO}_{2}$ exposure in a high outdoor $\mathrm{NO}_{2}$ environment is less important than in a low one. ${ }^{8}$ In effect, outdoor $\mathrm{NO}_{2}$ would act as a competing risk factor for respiratory illnesses with indoor $\mathrm{NO}_{2}$ generated from gas cooking. Our study supports this hypothesis. The frequencies of household gas cooking showed a doseresponse relation with respiratory illnesses only in the less polluted estate $\mathrm{B}$.

The lack of a significant association between passive smoking and respiratory illnesses in preschool children have been reported elsewhere. ${ }^{11-13}$ Our findings might be explained by a voluntary abstinence of smoking by parents in the presence of their preschool children.

Because most households used either an extraction fan or hood, the statistical power to detect a reduction in the risk of respiratory illnesses with the regular use of an extraction fan or hood in kitchen was low. Likewise, the adjusted OR of respiratory illness among children from households where windows were usually kept open were statistically insignificant.

\section{Limitations to the study Confounding factors}

The presence of siblings in the household, the use of day care centres by the children, and a history of allergic diseases are potential risk factors for respiratory illnesses. Seventy five per cent of households had only one child. The crude prevalence of respiratory illnesses among single children was almost the same as that among children with siblings, and separate analysis of the former yielded similar results. The use of day care centres is an uncommon practice among working mothers. After adjusting for working mothers, we found little change in our results. However, we have not sought specific histories of allergic diseases. To address subjective perception of air pollution as a possible source of recall bias, we compared the results in the models with and without the variable "self-satisfaction with indoor air quality". After this adjustment, the dose-response relation between gas cooking and respiratory illnesses persisted.

\section{Biases and validity}

Recall bias or misclassification of the children's respiratory illnesses is difficult to assess. Assuming that the frequency of gas cooking was unlikely to change during the one month period when data on cooking frequency were sought, any inaccuracies in the recall of the "exposure" data should be small. Systematic differences between the residents in the two estates are unlikely to have accounted for our findings. Residents of both estates, apart from their exposures to different levels of air pollutants, were similar in the floor areas of their apartments and their socioeconomic and demographic characteristics. Hence, our results are internally valid. As only preschool children were studied in two purposively chosen estates with contrasting levels of outdoor air pollutants, our results may not be generalisable to other estates, or to other subjects such as older children or adults.

\section{Exposure assessment and causal relation}

We lack measurement data on $\mathrm{NO}_{2}$ and other indoor air pollutants. However, it is reasonable to assume that a higher frequency of gas cooking produces a higher concentration of indoor $\mathrm{NO}_{2}$. Besides generating $\mathrm{NO}_{2}$, gas cooking also produces cooking oil fumes and other thermal combustion products. Therefore, the health impact of gas cooking on the children's respiratory health might have resulted from coexposure to both $\mathrm{NO}_{2}$ and cooking fumes. Good household ventilation can reduce the level of both pollutants, ${ }^{10}$ and the OR of using exhaust fans or hoods is below unity (but statistically insignificant). The lack of a temporal relation between exposure and health consequences is an inherent limitation in a cross-sectional study, and the association between the respiratory illnesses and gas cooking cannot be interpreted as a causal relation. Nevertheless, it is unlikely that an increased prevalence of respiratory illnesses in children would cause a higher frequency of domestic cooking. In the absence of other explanations, our findings support the hypothesis of a causal relation between gas cooking and respiratory illnesses among preschool children.

In summary, we have observed a significant, dose-response relation between the frequency of household gas cooking and the risk of respiratory illnesses among preschool children living in a low pollution estate in Hong Kong. As household gas cooking is common in most urban communities, the findings could have important public health implications. Further studies on the nature and chemical composition of fumes generated by cooking and their influence on health should give more insight in the research on indoor air pollution.

\section{ACKNOWLEDGEMENTS}

We would like to express our thanks to the residents of the two estates for their participation in this study, and to the Tsuen Wan District Board of the Hong Kong Government for funding the study.

\section{Authors' affiliations}

T W Wong, T S Yu, H J Liu, A H S Wong, Department of Community and Family Medicine, The Chinese University of Hong Kong, 4/F, School of Public Health, Prince of Wales Hospital, Shatin, NT, Hong Kong 


\section{REFERENCES}

1 Dennekamp M, Howarth S, Dick CA, et al. Ultrafine particles and nitrogen oxides generated by gas and electric cooking. Occup Environ Med 2001;58:511-16.

2 Ware JH, Dockery DW, Spiro A, et al. Passive smoking, gas, and respiratory health of children in six cities. Am Rev Respir Dis 1984; 129:366-74.

3 Garrett MH, Hooper MA, Hooper BM, et al. Respiratory symptoms in children and indoor exposure to nitrogen dioxide and gas stoves. Am J Respir Crit Care Med 1998:158:891-5.

4 Wieringa M, Weyler J, Vermeire P. Absence of association between respiratory symptoms in young adults and use of gas stoves in Belgium. Lancet 1996;347:1490-1.

5 Holscher B, Heinrich J, Jacob B, et al. Gas cooking, respiratory health and white blood cell counts in children. Int J Hyg Environ Health 2000;203:29-37.

6 Jarvis D, Chinn S, Sterne J, et al. The association of respiratory symptoms and lung function with the use of gas for cooking. European Community Respiratory Health Survey. Eur Respir $J$ $1998 ; 11: 651-8$.
7 Comstock GW, Meyer MB, Helsing KJ, et al. Respiratory effects on household exposures to tobacco smoke and gas cooking. Am Rev Respir Dis 1981; 124:143-8.

8 Jarvis D, Chinn S, Luczynska C, et al. Association of respiratory symptoms and lung function in young adults with the use of the domestic gas appliances. Lancet 1996;347:426-31.

9 Goren Al, Hellmann S. Respiratory conditions among schoolchildren and their relationship to environmental tobacco smoke and other combustion products. Arch Environ Health 1995;50:112-18.

10 Farrow A, Greenwood R, Preece S, et al. Nitrogen dioxide, the oxides of nitrogen, and infants' health symptoms. ALSPAC Study Team. Avon Longitudinal Study of Pregnancy and Childhood. Arch Environ Health 1997;52:189-94.

11 Awasthi S, Glick HA, Fletcher RH. Effect of cooking fuels on respiratory diseases in preschool children in Lucknow, India. Am J Trop Med Hyg 1996;55:48-51.

12 Stein RT, Holberg CJ, Sherrill D, et al. Influence of parental smoking on respiratory symptoms during the first decade of life: the Tucson Children's Respiratory Study. Am J Epidemiol 1999;149:1030-7.

13 Munyard P, Bush A. How much coughing is normal? Arch Dis Child 1996;74:531-4.

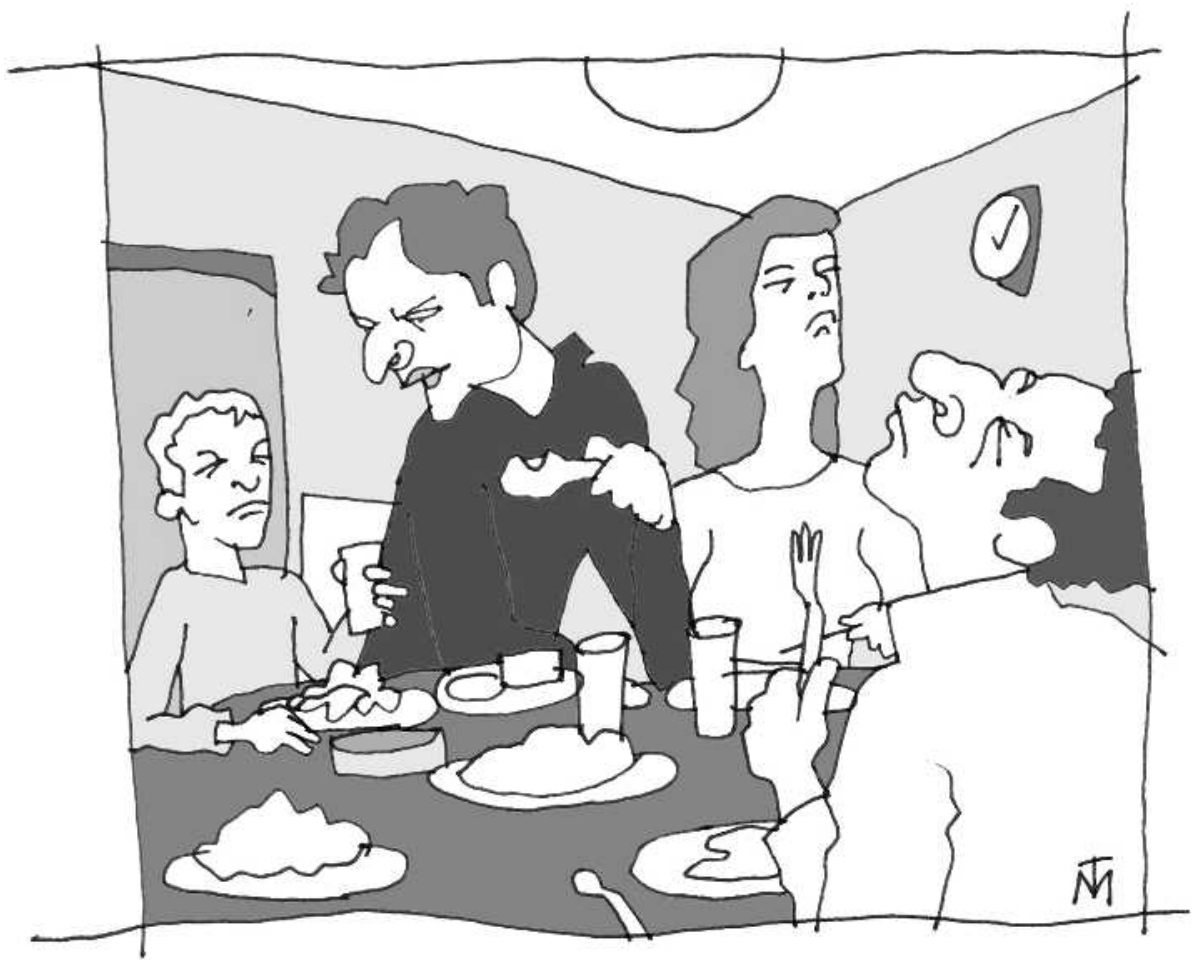

